\title{
WATER CONSERVATION ASPECTS OF GREEN BUILDINGS
}

\author{
Oindrila Das, Priyanka Bera ${ }^{1}$, Sanjib Moulick ${ }^{2}$ \\ ${ }^{I}$ M. Tech Student, School of Civil Engineering. KIIT University, Bhubaneswar, Odisha, India \\ oindrila.das24@gmail.com, priyankabera2909@gmail.com \\ ${ }^{2}$ Senior Associate Professor, School of Civil Engineering. KIIT University, Bhubaneswar, Odisha, India \\ sanjibmoulick72@gmail.com
}

\begin{abstract}
The Earth's surface is filled with water by $71.7 \%$, but only 3\% of this water can be used as potable water. In the present days, with the rapid increase in population water conservation has become a major issue. Green buildings are being created around the world to minimize the use of resources, reduce various harmful effects to the ecology and create a clean environment. With the increasing demand for water it has become a necessity to implement water conservation in the design of green buildings. This paper overviews the prioritization of water conservation as one of the important aspects of green buildings to save water. Various water efficient technologies such as water cooling towers and rain water harvesting are being implemented around the world. Countries such as Taiwan and Jordan have taken major steps towards implementing water efficient technologies into their green building designs. They have introduced water conservation index to evaluate the consumption of water and the water saving efficiency of the green buildings. Different rating systems have been introduced to establish the degree of accomplishment of environmental goals of the green buildings. Hence, it has been concluded that by using these water efficient techniques, the precious water can be saved in an economic way so that our future generations don't face the curse of water scarcity.
\end{abstract}

Keywords: water efficient technologies, water conservation index, rating systems

\section{INTRODUCTION}

Green building refers to a structure which is designed to be environmental friendly and make minimal and efficient use of resources. A green building is eco-friendly and resource efficientduring its whole life span starting from its construction to demolition. Green building design mainly emphasises on making efficient use of resources such as energy, water, etc. while reducing various bad effects on the environment and the occupants during its use. Many innovative technologies such as use of solar panels, green roofs, rain gardens, rain water harvesting, recycling and reuse of grey water, etc. are being used nowadays.

"Green building is perhaps best understood as a convergence of two movements: (1) an architectural movement emphasizing environment conscious, integrated, efficient, and innovative design; and (2) an environmental movement arising from the principle of sustainable development" ${ }^{\text {"[1] }}$.

The five main components of green buildings include site and design efficiency, reduced energy usage, reduced water consumption, environmentally safe construction materials and better air quality. This paper focuses on the water use efficiency and water conservation aspect of green buildings and its importance.

\section{WATER CONSERVATION}

The sources of fresh water which can be used by humans in their daily lives are limited. With the rapid increase in population the demand for water is also growing. The current population of the world is approximately 6.7 billion with a growth rate of around 80 million people every year. This implies that the need for freshwater is increasing by a rate of 64 billion cubic meters per year. By the year 2001 the global per head water supplies decreased by almost one-third of the value in the year 1970 due to the rapid increase in population. According to UN, by the year 2050 two-third of population or as many as 5 billion people will face shortage of clean freshwater ${ }^{[2]}$. At this rate all the fresh water resources will get exhausted and the world in future will face water scarcity. Thus, there is a dire need for conserving water and preventing its pollution.

One of the main objectives of green buildings is to reduce water use and protect its quality. Water conservation during the whole life span of a building can be achieved by designing dual plumbing that recycles the water used in water closets and the water used to wash cars, using water efficient fittings and fixtures such as ultra-low flushing toilets, bidets and low flow shower heads. Other technologies such as rain water harvesting and recycling and reuse of grey water, etc. are also being used.

\subsection{Rating Systems for Water Efficiency}

Many different rating systems for green buildings have been developed by various countries around the world in order to rate the green buildings according to degree of the environmental goals that have been achieved by them. Green buildings are rated based on their performances in energy efficiency, water conservation, indoor air quality, etc. 
The Building Research Establishment Environmental Assessment Method (BREEAM) was the very first system developed to rate green buildings. Following that, many other rating systems like Green Star in Australia, the Comprehensive Assessment System for Building Environmental Efficiency (CASBEE) in Japan, the Building and Environmental Performance Assessment Criteria (BEPAC) in Canada, and the Leadership in Energy and Environmental Design (LEED) inthe United States were devisedand currently are being used all over the world. Very detailedrecords of all the available assessment tools for safe environmental conditionscan be found in Ding, the Whole Building Design Guide, and the World Green Building Council $^{[3]}$.

\subsection{Water Efficiency (WE) In the LEED Green Building Rating System}

The Leadership in Energy and Environmental Design (LEED)was launched by USGBC as a new green building rating system in late 1998, and it has since become "the most widely accepted program of its kind in the U.S." LEED is a rating system that scores performance in five categories: (1) sustainable site design, (2) water conservation, (3) energy savings, (4) selection of materials and their usage, and (5) quality of indoor environment. USGBC has tailored LEED ratings systems for a range of different types of buildings, including new constructions and large renovations, operations and maintenance of the existing structures. ${ }^{[1]}$ LEED is being used in many countries which do not have any proper rating systems for their green buildings. Countries such as Brazil and Mexico have started implementing LEED in their green building designs.

The LEED rating is based on a system of points and credits. It awards points to the building under consideration based on its accomplishments in the five categories mentioned above. Water conservation being a major issue, LEED is implemented in different kinds of buildings to analyse and rate the extent of water efficiency being achieved by the building.

\section{I.LEED rating for New Construction}

The LEED rating for New Construction ("LEED-NC") was the first rating system proposed by USGBC and is the standard for the all other LEED rating systems. According to this rating system, various buildings are certified as "Platinum", "Gold", "Silver" and "Certified," based on the no of points they obtain in the five categories mentioned above with "Platinum" being the highest rating. A total sixty-nine points can be obtained out of which the category of water efficiency comprises of a total of five points. These five points are awarded as: a 50\% decrease in the use of potable water for irrigation (1 point), a $100 \%$ decrease in the same (1extra point), a $50 \%$ decrease in the use of potable water in sewage transportationof the building (1 point), a $20 \%$ decrease in cumulative water usage according to a baseline defined for the building (excluding irrigation) after satisfying the performance requirements for fixtures of the Energy Policy Act of 1992(1 point), and a 30\% decrease in the same ( 1 extra point). ${ }^{[1]}$

\section{II.LEED Rating for Existing Buildings}

The LEED rating for Existing Buildings ("LEED-EB”) comprises of anoverallof eighty-five points and awards the same four certification levels as that of LEED-NC. The LEED-EB system includes two mandatory water efficiency measures: (1) reduction of "fixture potable water usage to a level equal to or below water use baseline, calculated as $120 \%$ of the water usage that would result if $100 \%$ of the total building fixture count were outfitted with plumbing fixtures that meet the Energy Policy Act of 1992 fixture performance requirements"; and (2) the obedience of required polluted waste discharge according to the Clean Water Act, if the building is structured under the EPA's pollution discharge elimination program. Once those prerequisites are satisfied, an existing building renovation can achieve water efficiency points by obtaining a $50 \%$ (1 point) or $95 \%$ ( 1 extra point) decrease in the use of potable water for irrigation purposes.Another point can be earned by decreasing the use of potable water for sewage transportation of the building by $50 \%$ or doing $100 \%$ wastewater treatmenton the site to tertiary standards. Obtaining $10 \%$ or $20 \%$ decrease in fixture water use according to the base-line results in awarding of one or two extra points, respectively. This distribution of points is essentially same as that in the LEED-NC, except that the required reductions are slightly lesser. ${ }^{[1]}$

\section{III.LEED Rating for Homes}

The LEED rating for Homes, which is currently in a trial period, contains a total of 108 points. The awarding of points for water efficient techniques in this system arestricter. A designer earns points due to the installation of a rainwater harvesting system (1 point) or grey water recycling and reuse system (1 point), design and installation of highly efficient irrigation systems (up to 5 points, depending on the climate of the region), and installation of highly efficient lavatory faucets, shower heads, and urinals (up to 3 points). ${ }^{[1]}$

\subsection{Water Conservation Index}

"The water conservation index is the ratio of the actual quantity of water consumed in a building to the average water consumption in general. The index is also called, the water saving rate". ${ }^{[4]}$ Assessments ofwater usageby buildings including the quantity of water usage as well as the quantity of water conserved due water efficient fittings, rain water harvesting and recycling and reuse of grey water.

As water has become a limited resource, it is required to evaluate the water being consumed by all the buildings. Thus, water conservation index comes into play in order to calculate the water saving rate of each building and then assess whether the building can be certified as a green building or it has to implement water efficient techniques into its design and accordingly renovate it. The water conservation index also helps in designing a new building according to the required water consumption quantity. 
The actual water saving rate (WR) is used for residential buildings only and a building having WR less than 0.8 can be categorised under green buildings. ${ }^{[4]}$ For calculating the water saving rate in buildings other than residential buildings, the rate of adoption of water saving equipment (AR) is used. Any building other than a residential building needs to have an AR value of less than 0.8 is qualified to be identified as a green building ${ }^{[4]}$.

According to this approach, projects in order to be qualified as green buildings should attain a water saving rate of more than $20 \%{ }^{[4]}$ It is not only aimed at water conservation in existing buildings but also to promote green building design and construction for upcoming construction projects. This system is currently being used in Taiwan and rapidly gaining recognition around the world.

\section{WATER EFFICIENT TECHNOLOGIES}

Water efficiency refers to the decrease in the usage of water as well as decrease in the wastage of water. Wastage of water or its extra usage leads to drawing out of more water from the fresh water resources, resulting in their depletion. Thus, water efficient technologies have been developed to conserve potable as well as non-potable water and to ultimately save the already limited fresh water resources. Water efficient technologies in buildings mainly include water saving fittings and fixtures. They also include rain water harvesting and recycling and reuse of grey water.

A study of household water consumption in different areas revealed that almost $50 \%$ of the total water is used in baths and toilet flushes. ${ }^{[4]}$ Thus, instead of using luxurious but water wasting fittings and fixtures, water saving ones can be used. These include used of low flow shower heads and low flushing toilets instead of bathtubs and normal flushes, which use more water respectively. Other such fittings and fixtures such as two-sectioned water closets, bidets, composting toilet systems, dry urinals, auto sensor water taps etc. But the major water saving is done by rain water harvesting and grey water recycling and reuse.

\subsection{Rain Water Harvesting}

It is the collection and distribution of rainwater for using in daily life, rather than allowing it to run off. Rainwater is generally accumulated from roof tops. Then it is deposited in a reservoir with percolation. It is used for gardening, cultivation and domestic uses. The harvested water can also be used as ground water recharge.

Water shortage is caused by climate change, lack of planning of water uses, rapidly increasing water pollution and increasing population.

According to studies, if more supplies of freshwater aren't found by 2020 Sudan, Venezuela, Ethiopia, Tunisia and Cuba will face sever water scarcity. By 2035 Himalayan glaciers will disappear leaving India, Myanmar and Bangladesh in the state water shortage.
So, under such dire conditions some serious steps towards conservation of water must be taken. Rain is a natural source of water. So, if it can be collected and treated, it can be used as potable water. It is a cheap and simple technology, so it can be easily installed in normal households and a lot of water can be saved.

\subsubsection{Stages in Rainwater Harvesting}

A basic system for the harvesting of rainwater consists of three stages:

\section{Collection Stage}

It is the first step of Rainwater harvesting. At first while it's raining in a catchment area, rainwater is collected in a container on roofs, pavement or the soil surface. Channels all around the edge of a sloping roof to collect and transport rainwater to the storage tank.

\section{Distribution Stage}

Pipelines are the backbone of the distribution system in RWH. They carry rainwater from the catchment or rooftop area to the harvesting system. They can be semi-circular or rectangular and are made using galvanized iron sheet (20 to 22 gauge), PVC, Bamboo. Table 1 shows diameter of pipe required for drainage of rainwater according to rainfall intensity and area of the roof ${ }^{[5]}$

\section{Storage Stage}

After collection and distribution, next comes the most important step, the storage system. For simple RWH storage tank is used. The capacity of the storage tank is based upon several design criteria:

- rainfall

- the length of dry season

- estimated need

The increasing requirement of water is resulting in lowering of ground water table. The rainwater recharges the ground water. This water is available in lakes, rivers, ponds, aquifers, etc. but these are fickle sources. Treated rainwater can solve the demand of household water needs. Generally the water sources are located far from community. If rainwater can be collected and used, it will reduce the cost of distribution.

\subsection{Grey Water Recycling and Reuse}

Greywater refers to the domestic waste water which is drained out excluding the waste water from kitchen sink and the water closet as they have high concentration of organic matters. ${ }^{[8]}$ In order to conserve water this water cannot be just drained out but should be recycled and reused. The benefit of using recycled greywater is that it is a large source with low concentration of organic matter. ${ }^{[6]}$

The bathroom greywater consists of waste water from showers, bathtubs and wash basins. It has a very low concentration of organic matter. The other sources of greywater are from washing of clothes, car washing, etc. 
According to various studies, an average household produces 140 litre of greywater per day ${ }^{[6]}$. The various sources and their contribution is categorized in table 2 .

The greywater from all these sources are collected and then treated to make them safe for non- potable use. These treatments include passing the greywater through sand filters or by using natural coagulating agents or by electrocoagulation techniques. Also other biological and chemical treatments. It has been found that using recycled greywater can support the quantity of water required for water closets, car washing and garden watering.

\subsection{Cooling Towers}

Green buildings use evaporative cooling systems to save energy. These systems use water for cooling. Keeping in mind the need for conservation of water, the water used in these cooling systems is non-potable water. The circulated water is not drained out but is recycled again used in cooling towers. Using cooling towers which recycle almost $95 \%$ of the total water are recommended. ${ }^{[8]}$

\section{SYSTEMS DEVELOPED FOR ENCOURAGINGWATER CONSERVATION} AROUND THE WORLD

In Santa Clara Valley Water district, the municipal water agencies incorporate various "policy instruments" [9] to develop efficient water usage among their consumers. Schneider and Ingram (1990) ${ }^{[9]}$ defined three main categories of policy instruments in water resource management. They are authority tools, incentive tools and capacity building tools. ${ }^{[5]}$ In authority tools the governing body implements directives that restrict the quantity of water usage and adoption of water efficient technologies by their consumers. In incentive tools, the consumers are not forced but are given a choice. Such as, consumers saving more water or installing water saving appliances are given rebates on their water consumption bills whereas others are not. In capacity building tool, it is assumed that the consumers do not have adequate knowledge or technology to make the required changes but if given the choice they would opt for the right choice of their own free will. So, capacity building tools take into account the fact that the consumers are willing to make changes in their water usage if provided with adequate information and infrastructures. Jordan has limited sources of fresh water and has one of the lowermost distribution per head. Thus, with increase in population, the per capita distribution decreases even further, as a result Jordan will face an absolute problem of water scarcity in the near future. Hence, Jordan started incorporating green building practices in their designs. They also developed an assessment tool called SABA ${ }^{[10]}$ green building rating system to evaluate the green buildings in Jordan. SABA is a "criteria-based tool" [10] and it assigns points based on the satisfaction of its seven categories namely, site design (10.3), energy savings (23), water conservation (27.7), resources and materials used (10.3), environmental quality inside the building (11.8), wastage and pollution (6.4), and economic (10) ${ }^{[10]}$. A total of 100 points can be earned and the building under consideration can be categorized as - very green (100-80\%), green (79$50 \%)$, not green $(<50 \%){ }^{[10]}$ This system takes into account only residential buildings and their surrounding environmental conditions which is native to the region of Jordan.

Water conservation index is used in Taiwan to evaluate the water saving rates of various buildings. Taiwan has a high average annual rainfall rate of $2500 \mathrm{~mm}{ }^{[4]}$. But the water distribution per person is very low and due to luxurious lifestyle of the people, there is lot of unnecessary wastage of water (such as stylish shower heads, bathtubs, etc.). Hence, with increase in population, the water demand is also increasing, resulting in water shortage problem and a need to conserve water in Taiwan. So, water conservation index was devised to encourage the efficient usage of water, harvesting of rain water, recycling and reuse waste water and most importantly discourage the wastage of water.

Brazil contains $12 \%$ of the world's total water but it is unevenly distributed and most of its rivers are polluted. Furthermore, not even $10 \%$ of sewage is treated and reused. [11] Thus, it gave rise to a need for water conservation to avoid further wastage of water when the world is going to face global water crisis in the near future. Brazil has yet to implement any green building assessment plan but studies are conducted in order to assess the water supply systems and waste water drainage systems in the residential buildings in Brazil. These studies aim at developing an assessment tool to encourage green building practice in Brazil.

\section{CONCLUSIONS}

The main objective of this paper is to highlight the rising need for water conservation in today's world and its importance as a part of green building designing and construction. The necessity for water conservation has become so much significant that recently LEED rating systemhas doubled the points under the water efficiency category to ten from the previous quantity of five. Several countries around the world have already started devising green building designs in all their construction works with special emphasis on water conservation and are encouraging their citizens to use water efficient technologies. Numerous rating systems to evaluate the efficient use of water in buildings have been brought into practice. Protection of the remaining fresh water resources around the world has become a matter of global significance and measures are being taken to preserve them so as to avoid facing the problem of water scarcity in the future.

\section{REFERENCES}

[1]. Nelson,P.A., "Measuring from the High Watermark: Defining Baselines for Water Efficiency in Green Buildings", New York University School of Law, Columbia University, 2007, pp.114-117.

[2]. Moghadam,B.Z., "Introducing Water Efficiency of U.S. Green Building Council's LEED Program to the 
freshmen of the Technology College", Architecture and Construction Management Department of the Farmingdale State College, pp.1.

[3]. Lacouture,D.C., Sefair,J.A., Flo'rez,L., Medaglia,A.L., "Optimization model for the selection of materials using a LEED-based green building rating system in Colombia", Building and Environment 44, 2009, pp.1163.

[4]. Cheng,C.L., "Evaluating water conservation measures for Green Building in Taiwan",

[5]. Department of Architecture, National Taiwan University of Science and Technology, Building and Environment 38, 2003, pp.370-372.

[6]. Rain water harvesting and conservation manual CPWD, Govt. of India, 2002, pp.17.

[7]. Pidou,M., Memon, F.A., Stephenson,T., Jefferson,B., Jeffrey,P., "Greywater recycling: A review of treatment options and applications", Engineering Sustainability 160 issue ES3, 2007, pp.119.

[8]. Lambe,J.S., Chougule,R.S., "Greywater - Treatment and Reuse", IOSR Journal of Mechanical and Civil Engineering (IOSR-JMCE), pp.21.

[9]. Cline, Daryn,S., "Interpreting and Applying Cooling Tower Water Efficiency Design Recommendations in Sustainable Building Codes", American Society of Heating, Refrigeration and Air Conditioning Engineers, Inc., volume 120, 2014.

[10]. Reed,L.K., "Capacity Building as A Policy Instrument in Water Conservation: A Case Study on Commercial, Industrial, and Institutional Consumers", July 2012, pp. 3919-3821.

[11]. Ali,H.H., Nsairat,S.F.A., "Developing a green building assessment tool for developing countries - Case of Jordan", Building and Environment 44, 2009, pp.1060,1062.

[12]. Ilha,M.S.O., Oliveira,L.H., Goncalves,O.M., "Environmental assessment of residential buildings with an emphasis on water conservation", Building Serv. Eng. Res. Technol. 30,1, 2009.

\section{TABLES}

Table 1. Diameter of pipe required according to average precipitation and area of the roof ${ }^{[5]}$

\begin{tabular}{|c|c|c|c|c|c|c|c|}
\hline & \multicolumn{7}{|c|}{ Average rainfall(mm) } \\
\cline { 2 - 7 } & 50 & 75 & 100 & 125 & 150 & 200 \\
\hline Diameter of pipe (mm) & \multicolumn{7}{|c|}{ Roof Area $($ sgm) } \\
\hline 50 & 13.4 & 8.9 & 6.6 & 5.3 & 4.4 & 3.3 \\
\hline 65 & 24.1 & 16 & 1 & 9.5 & 8 & 6 \\
\hline 75 & 40.8 & 27 & 20.4 & 16.3 & 13.6 & 10.2 \\
\hline 100 & 85.4 & 57 & 42.7 & 34.2 & 28.5 & 21.3 \\
\hline 125 & - & - & 80.5 & 64.3 & 53.5 & 40 \\
\hline 150 & - & - & - & - & 83.6 & 62.7 \\
\hline
\end{tabular}

Table 2. Sources of grey water and their contributions

\begin{tabular}{|l|l|l|l|}
\hline Sl. No. & Source & Type & $\begin{array}{l}\text { Quantity/day/pers } \\
\text { on }\end{array}$ \\
\hline 1 & Shower & Greywater & $20-30 \mathrm{lit}^{[7]}$ \\
\hline 2 & $\begin{array}{l}\text { Washing } \\
\text { cloth }\end{array}$ & Greywater & $15-20 \mathrm{lit}^{[7]}$ \\
\hline 3 & Pets & Greywater & $10-15 \mathrm{lit}^{[7]}$ \\
\hline
\end{tabular}

